\title{
Data Acquisition System Which Applied To the Growth of Palm Oil Using Mamdani Adaptif Neural Fuzzy (M-ANFIS)
}

\author{
N. Suryaningsih ${ }^{1}$, F. Busalim ${ }^{1}$, W. Broto ${ }^{1}$, and A. Prasetyowati ${ }^{1}$
}

\begin{abstract}
The data acquisition device can be used to acquire the analogical and digital signals such as a control variable period of growth of oil palm trees with tall stems knowing commonly called a biological signal. In this case, we will apply it to control the growth rate of oil palm plantations. Oil palm growing conditions can be monitored more carefully using the data acquisition (DAQ). DAQ devices have analog inputs that can process data measurement instruments, such as the rate of growth of oil palm plantations. Control of the data acquisition system using adaptive neuro fuzzy methods (ANFIS). In this research, we make a comparison of data acquisition using ANFIS method with data acquisition without ANFIS method. Data acquisition is expected to know the tall of the stems of oil palm trees with three categories to $5 \mathrm{~cm}$ to $10 \mathrm{~cm}$, the status of planting, $11 \mathrm{~cm}$ to $200 \mathrm{~cm}$ treatment status and $200 \mathrm{~cm}$ to $300 \mathrm{~cm}$ harvest status. Without using ANFIS method, the resulting data acquisition can not know the status of the harvest with a reading error rate of 0.9, while using ANFIS method of data acquisition can know the status of the harvest with an error rate of reading data on the plant by 0,084 on a long learning (epoch) of 9 . Without using ANFIS method, the resulting data acquisition can not know the status of the harvest with a reading error rate of 0.9 , while using ANFIS method of data acquisition can know the status of the harvest with an error rate of reading data on the plant by 0,084 on a long learning (epoch) of 9. For epoch level attempted level from 1 to 11, in epoch 1 to 8 instructional error rate for 0274 , as well as epoch to 10 and 11.
\end{abstract}

Keywords: DAQ, oil palm, ANFIS, Height rod, epoch

\section{INTRODUCTION}

The use of industrial process automation and digital signal processing systems for a range results in the need to simplify data collection tasks that require low cost. For example, examine the oil palm plantation area is very spacious.[1] The method exploits the way the user would need extra expensive and quite a long time at the time of acquiring the condition of plant growth in the oil palm plantations have a fairly wide area. The manual way to acquire oil palm plant growth data have many weaknesses. Constraints manually collecting data in the field of which started from paper easily damaged or even lost, as well as factors that bad weather such as rain can also damage the paper becomes a medium of information collection growth of any plant oil palm. Use of the data acquisition system can overcome the weakness factor in the growth of the data collection process every palm tree. Data acquisition will be made on this research-based adaptive neural fuzzy (ANFIS).

\footnotetext{
${ }^{1}$ Department of Electrical Engineering, Pancasila University, Indonesia
}

Data acquisition systems growth of palm trees is expected to provide accurate information about the status of oil palm growth.

\section{DATA ACQUISITION SYSTEM BASED MAMDANI ADAPTIVE NEURO FUZZY}

This paper presents a data acquisition system using neuro adaptive fuzzy (ANFIS) with mamdani method, which is usually called M-ANFIS. Neural networks have a major function of dealing with data that is not right with the training, while the fuzzy logic can handle the uncertainty of human cognition. Neural networks and fuzzy logic has been integrated very well. Fuzzy neural network implement the main steps in the fuzzy inference ordered layer neural network with a specific architecture so that the weight to be arranged in a network that makes the fuzzy inference is closer to the actual situation with the learning capability NN. [3] This paper will introduce a model of Mamdani based Adaptive Neural Fuzzy Inference System (M-ANFIS), which has the advantage of greater ANFIS in the expression of a consistent and intuitive part of fuzzy reasoning. This model will reflect the nature of CI lots more. M-ANFIS network structure can be seen in Figure 1

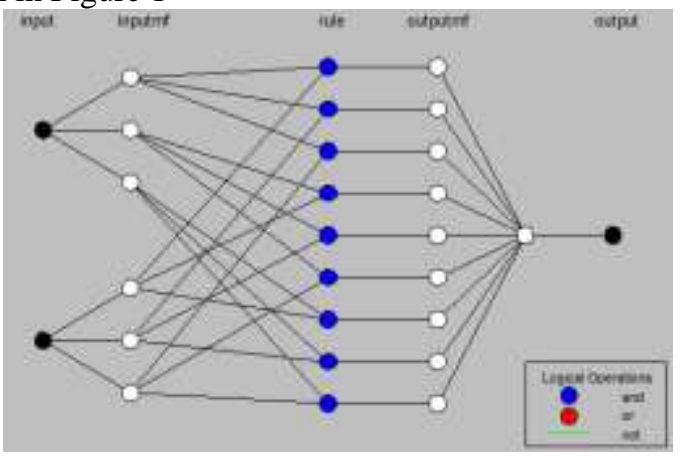

Fig. 1. Structure Mamdani Network ANFIS

Fuzzy method works by determining weights for each input and fuzzy rules when processing a multi-parameter analysis of synthesis. Mamdani fuzzy inference method showed gains in output expression on the data acquisition system are examined in this study. To determine the operating method of Mamdani fuzzy inference, need to set the functions of the operator as follows:

1) AND operator (usually T-norm) to shoot the strength calculation rule with his predecessor AND'ed

2) OR operator (usually T-conorm) to calculate the buildup rule with his predecessor OR'ed 
3) Implication Operator (usually T-norm) to calculate Membership Function (MFS) which qualify under the given firepower.

4) Aggregate Operator (usually T-conorm) to combine MFS qualified to produce the overall output of the MF

5) Defuzzification operator to change the output MFsampai crisp single output value If the operator AND operator and the implication is that the product, and aggregate operator is the number, is the area centroid defuzzification operator. Advantages of applying the method of the composite inference that the ANFIS Mamdani models have the ability to learn because differentiability during the calculation. [4][5]

The composition presents the following sum-product theorem [13], see Eq.1. crisp final output using centroid defuzzification equal to the average weighted centroid of the consequent MFS, by the following equation:

$$
\psi\left(\mathbf{r}_{\mathbf{i}}\right)=\omega\left(\mathbf{r}_{\mathbf{i}}\right) \times \mathrm{a}
$$

where, $\psi$ (ri) is the weighted factor of ri; ri is the ith fuzzy rule; $\omega$ (ri) is the firing strength of ri; $A$ is the area of the consequent MFS of ri. Mamdani models used have a block diagram like Figure 2 as follows:[6]

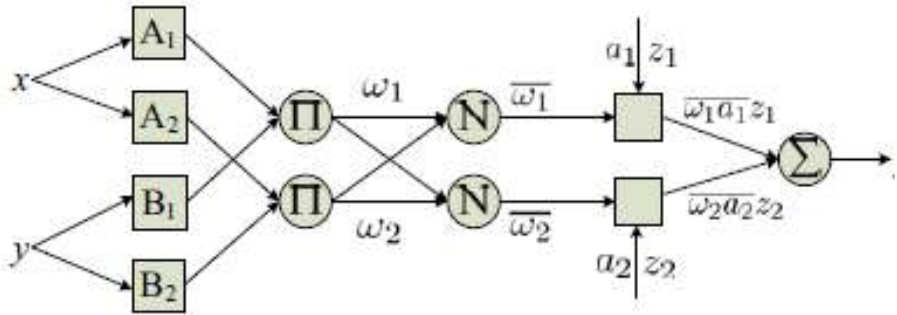

Figure 2. Block diagram models Mamdani ANFIS

Rule 1: If $\mathrm{x}$ is $\mathrm{A}_{1}$ and $\mathrm{y}$ is $\mathrm{B}_{1}$, then $\mathrm{f}_{1}=\omega_{1} \mathrm{a}_{1}$

. $\mathrm{z} 1$;

Rule 2: If $x$ is $A_{2}$ and $y$ is $B_{2}$, then $f_{2}=\omega_{2} a_{2}$

.$z 2$.

Mamdani ANFIS architecture consists of five layers, output of each layer is the following.

Layer 1: Generate the membership grades $\mu_{\mathrm{A}}, \mu \mathrm{B}$.

$$
\begin{aligned}
& \mathrm{O}_{1, \mathrm{i}}=\mu_{\mathrm{Ai}}(\mathrm{x}), \quad \mathrm{i}=1,2 ; \\
& \mathrm{O}_{1, \mathrm{i}}=\mu_{\mathrm{B}} \mathrm{i}-2(\mathrm{y}), \quad \mathrm{i}=3,4 .
\end{aligned}
$$

the membership function is the generalized bell function.

$$
\mu_{A i}(x)=\frac{1}{1+\left[\left(\left(x-c_{i}\right) / d_{i}\right)^{2}\right]^{b i}}
$$

where $\left\{b_{\mathbf{i}}, c_{\mathbf{i}}, d_{\mathbf{i}}\right\}$ is the parameter set referred to as premise parameters.

\section{Layer 2:}

$$
\begin{gathered}
\mathrm{O}_{2, \mathbf{i}}=\omega_{\mathbf{i}}=\mu \mathrm{Ai}(\mathrm{x}) \times \mu \mathrm{Bi}(\mathrm{y}) \\
\mathbf{i}=1,2 .
\end{gathered}
$$

Firing strength $\omega_{\mathbf{i}}$ is generated with product method.
Layer 3:

Layer 4:

$$
\mathrm{O} 3, \mathrm{i}=\omega \mathrm{i}=\omega \mathrm{i} / \omega 1+\omega 2, \mathrm{i}=1,2 .
$$

$\mathrm{O} 4, \mathbf{i}=\mathrm{f}_{\mathbf{i}}=\omega_{\mathbf{i}} \mathrm{a}_{\mathbf{i}} \mathrm{z}_{\mathbf{i}}$,

$$
\mathbf{i}=1,2 \text {. }
$$

where the consequent parameters $\mathbf{a}_{\mathbf{i}}, \mathbf{z}_{\mathbf{i}}$ are the area and center of the consequent MFs respectively.

\section{Layer 5:}

$$
\mathrm{O}_{5, \mathbf{i}}=\mathrm{f}_{\mathbf{i}}=\omega_{\mathbf{i}} \mathrm{a}_{\mathbf{i}} \mathrm{z}_{\mathbf{i}}, \mathbf{i}=1,2
$$

The overall output $\mathbf{f}$ is given. $\left\{b_{\mathbf{i}}, c_{\mathbf{i}}, d_{\mathbf{i}}\right\}$ are premise parameters and $\mathbf{a}_{\mathbf{i}}, \mathbf{z}_{\mathbf{i}}$ are consequent parameters which need to adjust. The type of membership functions (MFs) of the inputs are generalized bell functions, each $\mathrm{MF}$ has 2 nonlinear parameters; each consequent MF has 3 nonlinear parameters which are area and center of the consequent part. Totally, there is 6 parameters.

\section{Growth DAtA Design SyStem OF OIL PALM TREE}

In this section we will discuss the design of the automation system and data logger in terms of software and hardware for monitoring system activity and the development of oil palm plantations. In this system, the data logger can store activity with status "Plant", "treatment" and "Harvest" of the oil palm plantations with input from the high level of heavy bunch stems and fruit of oil palm plantations. Range tall stems include $5 \mathrm{~cm}$ to $10 \mathrm{~cm}$ have the status of "Plant", $11 \mathrm{~cm}$ to 200 $\mathrm{cm}$ has a "Treat" and $210 \mathrm{~cm}$ to $300 \mathrm{~cm}$ have the status of "Harvest", while the range for heavy bunch of fruit 8 to $11 \mathrm{~kg}$ status "Treat" and 12 above the status of "Harvest". Range is used as an input to the system ANFIS. It is made to the automation system can transmit data activity planting, harvesting and fertilizing or maintenance to a data logger. Automation system designed consists of several pieces of the device is a barcode scanner, Real Time Clock (RTC), Arduino, and SD card. Barcode scanners are used to read the ID on each tree so that it can avoid the mistakes of the identity of the tree. Real Time Clock (RTC) is used as the clock in the process of data storage. RTC helps in storing the data as the clock, because the RTC will not turn off when the main supply is removed. RTC has a backup power produced by the battery. All three of these devices are controlled by the Arduino Uno board with ANFIS method, results from a reading of the three devices will be saved into an SD Card 2GB in csv format (Microsoft Excel) as shown in FIG. In this system use LCD also a function to display the data based on the ID. The display on the LCD then recorded also at the computer in the data center. It is used for regular maintenance processes that help the system to work well so that the system failure can be avoided. Block diagram of the data acquisition system using M-ANFIS method shown in Figure 3 below: 


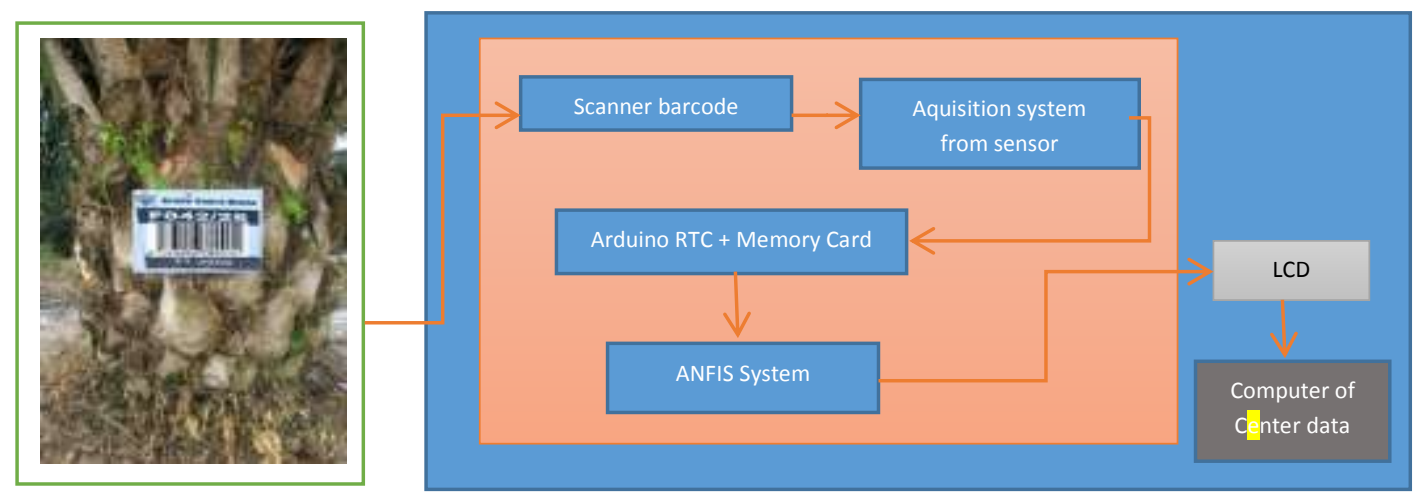

Fig. 3. Block diagram of the data acquisition system based on M-ANFIS

As stated above, our goal is to build a model that has the advantage of data acquisition can analyze status with accuracy on field conditions better. M-ANFIS method gives results of oil palm crop conditions in the field based on the data information from the sensor as an input acquisition system. Where M-ANFIS intelligently to determine the status of the tree in conditions outside of the rules given. In ANFIS, the output of each rule is a linear combination of input variables plus a constant, and the final result is the weighted average of the output of each of these rules. The level of service reflect the subjective feelings of the information delivered via a barcode from the sensor; clearly the true nature of Fuzzy models as these systems have a linear output. Model MANFIS able to resolve issues such as the condition of the oil palm trees are not in accordance with the rules provided, because the value of the output is presented as a function of membership of a simple linear equation. Model M-ANFIS reflect the true meaning of the determination of the status of the oil palm tree and logical reasoning user. Block diagram of the process of evaluating the status of the oil palm tree as shown in Figure 4

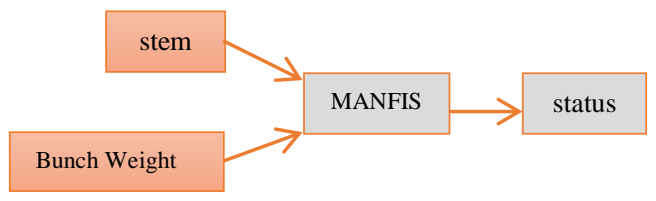

Fig. 4. Block diagram of the process of evaluating the status of the oil palm tree

\section{RESULT ANALYSIS}

All procedures were implemented with Matlab 7:13. Experiment data acquisition system using a sample of oil palm trees in pairs (1000 pairs for training and 300 for testing).

Mamdani inference system as shown in Fig.5.

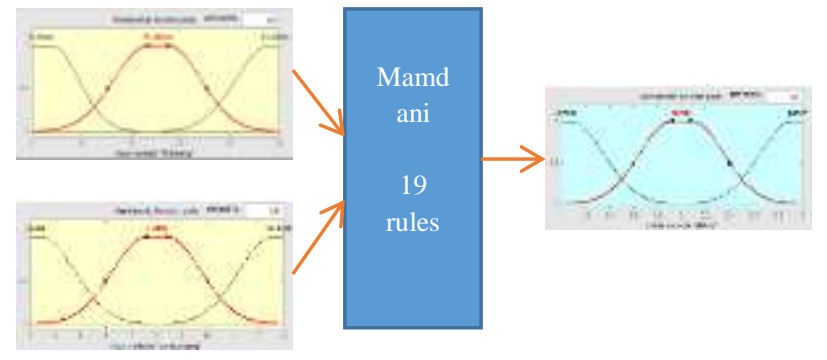

Fig. 5. Inference System Mamdani

As seen in Figure 5 above, the system of data acquisition using the M-ANFIS has two inputs, input first full-length trunks of palm trees that consists of three membership functions (MFS), which consists of three length variations trunk: 5-10 cm (MF1 ), 11-200 cm (MF2) and 210-300 cm (MF3), then input the second form of the weight of a bunch of fruit that consists of three variations: 4-7 $\mathrm{kg}$ (MF1), 8-11 kg (MF2) and 12 and above (MF3), while the output consists of three status: Planting Period, the maintenance and harvest. By using M-ANFIS, the reaction will be analyzed, the data acquisition system using M-ANFIS method can predict the likelihood of outside rules for example in the form of rod length between 5-8 $\mathrm{cm}$ but oil palm fruit bunch weight has reached $12 \mathrm{~kg}$. M-ANFIS method will give a permanent status in the duration of the treatment, this is because the rules given in this system, long stems greatly affect the status of the oil palm tree. Of the model rules as listed above have obtained graph learning process output data acquisition system palm tree with M-ANFIS methods such as figure 6 below:

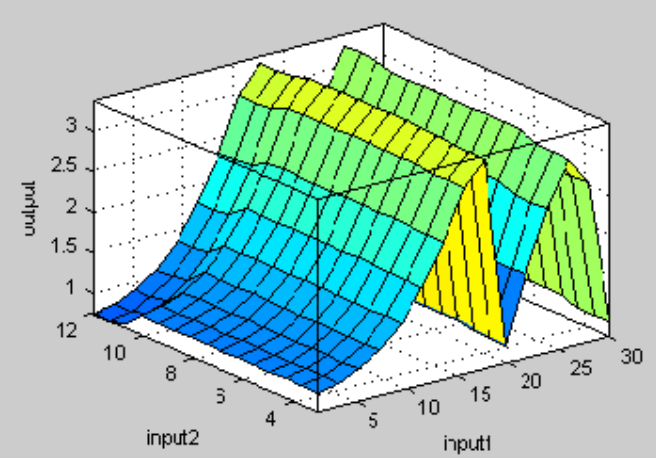

Fig. 6. Graph output process data acquisition M-ANFIS

In Figure 6, showing the relationship between the condition of rod length and weight of oil palm fruit bunch. M-ANFIS 
can intelligently determine the status and condition of oil palm plantations.

\begin{tabular}{|l|c|c|}
\hline \multicolumn{1}{|c|}{ TABLE.1 COMPARISON BETWEEN M-ANFIS AND ANFIS } \\
\hline & M-ANFIS & ANFIS \\
\hline Parameter Number & 45 & 126 \\
\hline Training Steps & 456 & 1024 \\
\hline Training Error & 0.152109 & 0.997767 \\
\hline
\end{tabular}

From the table above, it can be concluded that the Model MANFIS ANFIS models are superior in the number of adjustable parameters, scale training data, time-consuming and error testing. It is clear that M-ANFIS is more effective for small-scale sample data. In experiments, M-ANFIS, with $6 \mathrm{MFS}$ at the consequent.

\section{CONCLUSION}

Methods of computational intelligence has contributed to the smart data acquisition. Hybrid algorithms in this research has become a huge trend in computational intelligence. This study found that there are some famous types of hybrid algorithm called Fuzzy-NN and fuzzy computing evolution. In the process of fuzzy inference, ANFIS adopt linear equations in part consequently, the study proposes a model based adaptive Mamdani fuzzy inference system (M-ANFIS), which memilikikeunggulan greater part fuzzy consistent and intuitive thinking. All parameterdi M-ANFIS is a nonlinear parameter that can disesuaikandengan learn the rules discussed above. Finally, we use the M-ANFIS in the data acquisition process oil palm crop condition information. The experimental results show that the model M-ANFIS ANFIS superior models.

\section{REFERENCES}

[1] P. Dan, P. Tanaman, M. Cucumis, C. O. Sidauruk, J. Ginting, and J. Napitupulu, "1* , 2 , 2 1,” vol. 2, no. 2337, pp. 54-63, 2013.

[2] D. Ariyanto, I. W. Astika, and R. Setiawan, "Development of Data Acquisition Method of Spatial Macro Nutrient Content with EC Sensor and GPS,” J. Keteknikan Pertan., vol. 4, no. 1, pp. 107-114, 2016. https://doi.org/10.19028/jtep.04.1.107-114

[3] I. Maleki, L. Ebrahimi, S. Jodati, and I. Ramesh, "Analysis of Software Cost Estimation Using Fuzzy Logic," Int. J. Found. Comput. Sci. Technol., vol. 4, no. 3, pp. 27-41, 2014. https://doi.org/10.5121/ijfcst.2014.4303

[4] J.-S. R. Jang, C.-T. Sun, and E. Mizutani, "Neuro-Fuzzy And Soft Computing Jang: a computational approach to learning and machine intelligence." p. 640, 1997.

[5] A. Correa and A. M. Chauca, "System of data acquisition applied to a level control using fuzzy logic," 17th Int. Conf. Electron. Commun. Comput., pp. 13-13, 2007. https://doi.org/10.1109/conielecomp.2007.37

[6] Y. C. Y. Chai, L. J. L. Jia, and Z. Z. Z. Zhang, "Mamdani Model Based Adaptive Neural Fuzzy Inference System and its Application in Traffic Level of Service Evaluation," 2009 Sixth Int. Conf. Fuzzy Syst. Knowl. Discov., vol. 4, no. 3, pp. 739-746, 2009. https://doi.org/10.1109/FSKD.2009.76
Noor Suryaningsih received her Master Degree in University of Indonesia. She is a lecturer at Engineering Faculty of Pancasila University, Jakarta. Her research interest are related to telecommunica"on engineering, fuzzy logic and Remote sensing.

Fauzie Busalim received his Master Degree in Bandung Ins"tute of Technology, Bandung. He is a lecturer at Engineering Faculty of Pancasila University, Jakarta. His research interest are related to statistic and remote sensing.

Ane Prasetyowati is a candidate $\mathrm{PhD}$ in University of Indonesia. Her research interest include issues related to fuzzy logic, machine learning and artificial intelligent.

Wisnu Broto received his Master Degree in University of Indonesia. He is a lecturer at Engineering Faculty of Pancasila University, Jakarta. His research interest are related to computing engineering and fuzzy logic. 